\title{
Erratum to: Towards the Formal Reliability Analysis of Oil and Gas Pipelines
}

\author{
Waqar Ahmad ${ }^{1}$, Osman Hasan ${ }^{1}$, Sofiène Tahar ${ }^{2}$, \\ and Mohammad Salah Hamdi ${ }^{3}$ \\ ${ }^{1}$ School of Electrical Engineering and Computer Science (SEECS), \\ National University of Sciences and Technology (NUST), Islamabad, Pakistan \\ \{12phdwahmad, osman.hasan\}@seecs.nust.edu.pk \\ 2 Electrical and Computer Engineering Department, Concordia University, \\ Montreal, Canada \\ tahar@ece.concordia.ca \\ 3 Information Systems Department, Ahmed Bin Mohammed Military College, \\ Doha, Qatar \\ mshamdi@abmmc.edu.qa
}

\section{Erratum to: \\ Chapter "Towards the Formal Reliability Analysis of Oil and Gas Pipelines" in: S.M. Watt et al. (Eds.): Intelligent Computer Mathematics, LNAI, DOI: 10.1007/978-3-319-08434-3_4}

The original version of this chapter contained an error. The name of the author Waqar Ahmad was spelled incorrectly as Waqar Ahmed in the original publication. The original chapter was corrected.

The updated original online version for this chapter can be found at DOI: 10.1007/978-3-319-08434-3_4 